International Journal of Language Education

Volume 5, Number 4, 2021, pp. 396-408

ISSN: $2548-8457$ (Print) 2548-8465 (Online)

Doi: https://doi.org/10.26858/ijole.v5i4.19898

\title{
The Effects of Task-based Language Teaching and Audio-lingual Teaching Approach in Mandarin Learning Motivation
}

\author{
Chua Hui Wen \\ Universiti Malaysia Kelantan, Malaysia \\ Email: chua.hw@umk.edu.my \\ Lin Chia Ying \\ Universiti Pendidikan Sultan Idris, Malaysia \\ Email:lincuiyan@gmail.com \\ Ang Thiah Huat \\ Universiti Pendidikan Sultan Idris, Malaysia \\ Email:thuatang@gmail.com \\ Mohammad Affiq Bin Kamarul Azlan \\ Universiti Malaysia Kelantan, Malaysia \\ Email:affiq.ka@umk.edu.my \\ Fan Pik Shy \\ Universiti Malaya, Malaysia \\ Email:fanpikshy@um.edu.my \\ Shan Baoshun \\ Hangzhou Normal University, China \\ Email:yuyu371@hznu.edu.cn
}

Received: 23 March 2021

Reviewed: 1 July 2021-30 September 2021

Accepted: 5 December 2021

\begin{abstract}
This study investigates the effects of Task-based Language Teaching (TBLT) and the Audio-Lingual Teaching Approach (ALTA) on learning motivation among non-native Mandarin learners in the Teaching of Mandarin as a Third Language (TMTL). The TBLT applied is an adaptation of Willis's TBL Framework, while the ALTA applied is an adaptation of Sarıçoban's dialogue memorisation. A quasi-experimental design was used in this study, with 21 students selected through convenience sampling for TBLT and 22 students for ALTA. Motivational Strategies for Learning Questionnaire (MSLQ) was employed. A descriptive analysis was conducted to compare if any changes in learning motivation and learning anxiety components for both groups before and after TBLT and ALTA were adopted in the learning interventions. The descriptive analysis showed that there were changes in the aspect of learning motivation and learning
\end{abstract}


anxiety component. The result indicated that there was an increment in the number of students of the group with a very high level of learning motivation for TBLT. The result ranged from 8 students (38\%) to 11 students (52\%); the ALTA group remained unchanged as 11 students (50\%) had a high level of learning motivation, and 11 students $(50 \%)$ had a very high level of motivation. As for the learning anxiety component, the TBLT group showed a decrease in the number of students having very high anxiety, from 2 students $(10 \%)$ dropped to 0 student $(0 \%)$. Meanwhile, for the ALTA group, the results indicated that anxiety level for students had increased; the number of students who experienced a very high level of anxiety had increased from 2 students $(9 \%)$ to 6 students $(27 \%)$. The study indicates that TBLT has a positive effect on Mandarin learning motivation, which TBLT might help in reducing students' learning anxiety. Still, ALTA might, on the other hand, increase learning anxiety. The study implies that TBLT might be a better approach to learning Mandarin and might promote better performance among non-native speakers.

Keywords: Language teaching; TBLT; audio-lingual; ALTA; Mandarin; learning motivation

\section{Introduction}

The trend of economy's globalization appears more and more international communication and cooperation nowadays (Jie Ying et al, 2020) and Mandarin has become an important global language. It has official status in China and Taiwan and has 1,284 million native speakers worldwide. China's prominent growth in the world, both politically and economically, paired with Mandarin 's large numbers of speakers, has resulted in the increasing number of non-native Mandarin learners worldwide. Malaysia's education has taken note on the importance of Mandarin where its implementations can be seen in Malaysia education plans in recent years, such as the National Higher Action Plan 2007-2010, Malaysia Education Blueprint 2015-2025 (Higher Education) (MEB), and iCGPA Rubric Learning Outcomes Assessment Guide. All three policies above have mentioned the mastery of global languages, such as Mandarin, Arabic, French, Spanish, and other languages.

According to an unofficial interview conducted in Universiti Malaysia Kelantan (UMK), the feedbacks received from the learners suggested that mastering the Mandarin language by enrolling in a Mandarin course could help them in their prospects and enable them to communicate in Mandarin with their Chinese friends. However, at the same time, the learners also expressed about their fear of mastering the Mandarin language because they felt unable to achieve their desired outcomes, which is the ability to communicate that demotivate their Mandarin learning. This is due to the tonal phonetic system of the language that they first need to master as it is a challenging experience for them to master the four tones of Mandarin. This is because their native language, such as Bahasa Malaysia, Tamil and other languages in Malaysia, are not tonal languages. The same condition was recorded by Naimah (2005), whereby the learners are unable to communicate effectively in the language they learned (Tan, Ooi \& Hairul, 2016). This could be due to many causes such as the interference of their mother tongue and insufficient learning time (Cheun, 2006, as cited in Tan et al., 2016, Liu, 2018), as well as limited opportunities to use the target language daily (Jeon, 2005). These factors make the learners less motivated to learn the language. Through observation, attempts of using mother tougue to speed up students undertanding of Mandarin is common in Malaysia. Yet, the use of mother tongue in foreign language classes has been a controversial issue in the history of language teaching (Navidinia et al., 2018). Thus, it may be helpful for non-native Mandarin learners to be provided with an authentic, pragmatic use of the language for exposure in the classroom (Chua, Lin \& Azlan, 2018). 
Tan, Ooi, \& Ismail (2012), in their research, has suggested that Mandarin teachers should adopt a suitable teaching approach to take full advantage of the learning orientations, which are to fulfil language proficiency and communication skills as mentioned in MEB and iCGPA. Besides, to motivate learners, they have also suggested three conditions that teachers should create for the Mandarin course: (1) design communicative tasks and opportunities for their students to practice Mandarin and to apply the language by communicating with the Chinese community outside the campus, (2) encourage students to find suitable Mandarin-speaking peers as close friends to practice Mandarin, and (3) apply motivational strategies and learner-centered teaching methods to encourage students to participate more actively and collaborate in the learning process.

Hence, to solve the problem of limited Mandarin practice, Mandarin teachers often resort to practice the audio-lingual teaching approach (ALTA). The approach firstly requires learners to observe language models acting in certain situations. Later, learners are tasked to practice with a variety of drills, and the teacher emphasises the use of the target language at all times.

Besides that, researchers have also found that Task-based Language Teaching (TBLT) can boost learners' learning motivation (Park, 2012) by increasing their confidence, and at the same time, decrease their learning anxiety (Lopes, 2004). The results of the TBLT application can contribute towards learners having positive feelings in language learning as TBLT promotes fun and lively classroom atmosphere. According to NamazianDost et al (2017), the increase of learning motivation is influenced by learners' successful learning experience as it meets their expected outcome. Hence, through effective learning strategies, they undergo a successful learning experience. The successful learning experience could help them to consciously control how they learn so that they can be efficient, motivated, and independent language learners (Chamot et al., 1999; as cited in NamazianDost et al., 2017). Leaver \& Willis (2004) have presented the effect of TBLT, where TBLT is an excellent choice to motivate learners and promote higher levels of proficiency. Hence, East (2017) indicates that TBLT creates a low-anxiety learning environment where learners can express their ideas and practice their language to develop confidence. Thus, it believed that TBLT could influence learners' learning motivation efficiently and motivate them to learn successfully.

There is, therefore, a need to research on whether the application of ALTA and TBLT in Mandarin teaching and learning is suitable for non-native Mandarin learners, to see how effective can they be towards enhancing learners' motivation and their oral skills. Therefore, in the case of this research, non-native Mandarin learners' learning motivation and oral skills were taken into consideration in order to investigate the effectiveness of both teaching approaches.

Research objectives

The research objective of this research is to compare the changes in the learning motivation of non-native Mandarin learners between pre-treatment survey and post-treatment survey in Group A (TBLT) and Group B (ALTA).

Research questions and research hypothesis

Some researchers have found that learning anxiety is negatively associated with foreign language motivation (Gardner, Lalonde, Moorcroft, \& Evers, 1987; as cited in Hashimoto, 2002). On the same notion, Lopes (2004) mentioned that TBLT could boost learning motivation and, at the same time, decrease learning anxiety. Since learning motivation is linked to learning anxiety, hence, it is necessary for the research questions of this study to be constructed with the inclusion of learning anxiety apart from learning motivation. The research questions are as follows: 
a) Are there any changes in non-native Mandarin learners' learning motivation between pretreatment survey and post-treatment survey of Group A (TBLT)?

b) Are there any changes in non-native Mandarin learners' learning motivation between pretreatment survey and post-treatment survey of Group B (ALTA)?

c) Are there any changes in non-native Mandarin learners' learning anxiety between pretreatment survey and post-treatment survey of Group A (TBLT)?

d) d)Are there any changes in non-native Mandarin learners' learning anxiety between pretreatment survey and post-treatment survey of Group B (ALTA)?

The research hypotheses for the research questions above are shown as below:

a) There are no changes in non-native Mandarin learners' learning motivation between pretreatment survey and post-treatment survey of Group A (TBLT).

b) There are no changes in non-native Mandarin learners' learning motivation between pretreatment survey and post-treatment survey of Group B (ALTA).

c) There are no changes in non-native Mandarin learners' learning anxiety between pretreatment survey and post-treatment survey of Group A (TBLT).

d) There are no changes in non-native Mandarin learners' learning anxiety between pretreatment survey and post-treatment survey of Group B (ALTA).

\section{Literature review}

Task-based language teaching (TBLT)

Task-based language teaching (TBLT) is an approach applied in the teaching a second or foreign language, where it engages learners in an interactional authentic language environment by having them to perform a series of tasks (Murad, 2009) using the target language for communication. The activities in the task are something that relates to daily work, or in other words, the task is focused on real-life situations (Dailey, 2009). On the other hand, TBLT is a teaching approach that focuses on 'learning by doing', or process-oriented teaching approach, where communicative competence is the main objective. The communicative competence is not the ability to use the language correctly and appropriately like a native speaker, but it is about promoting the ability to communicate competently to accomplish a communication goal. TBLT aims not only to enable learners to acquire new linguistic knowledge but also to apply their existing knowledge. Hence, from this point, it could be said that TBLT involves both input-providing and output-prompting tasks, where a simple input-based task is used to build up target language proficiency.

Adaptation of Willis's task-based learning framework

According to Hung (2014), TBLT is strongly influenced by Willis (1996), Skehan (1998), and Lee (2000), in which the pedagogical tasks involve communicative language use where the user's attention is focused on meaning rather than grammatical form. Hence, from this point, TBLT fulfils the target of learning Mandarin regardless what teaching approach is applied, as Zhou (2008) asserted, the main focus is on communication and interaction, and less focus is put on the Chinese characters. Only a few Chinese characters that are monosyllable are introduced to learners during their language learning.

Willis's Task-based Learning Framework contains three main stages, as introduced by Prabhu (1987) in his Bangalore project. The main three stages include (a) pre-task (preparatory), (b) task or during task (meaning-focused, interaction process), (c) post-task (discussion - attending 
to form). Most researchers have applied these stages of the TBLT approach, including Willis (1996). However, in Willis's (1996) framework, private use and public use are added in the during task phase, where learners are requested to work with their peers to fulfil the task (private use), and they need to present in front of the class or play their video for the class (public use).

In this research, the adaptation of Willis's framework included the three main stages: pretask, during task and post-task, as well as the private and public use in the during task stage. In the during task stage of the framework, the public use was carried out through the implementation of natural learning of TBLT by requiring participants of the treatment group to conduct tasks with Chinese native speakers. Hence, the task for the treatment group does not only focus on the tasks undertaken between non-native Mandarin learners (private use), but also between non-native Mandarin learners and the Chinese native students (public use)..

\section{Audio-lingual teaching approach}

The audio-lingual teaching approach (ALTA) is a teaching approach that was supported by Skinner's Behaviourism theory. The theory assumed that human beings could be trained using a system of reinforcement. Correct behaviour receives positive feedback, while errors receive negative feedback. Hence, the basis of ALTA is to drill learners on grammatical sentence patterns (Larsen-Freeman, 2000). It is believed that sentence patterns of the target language can be acquired through conditioning by helping learners to respond correctly to stimuli through shaping and reinforcement. Hence, ALTA is an approach that stresses drilling to master the target language through memorisation and repetition. At the same time, mistakes are avoided in speech. It is also believed that substantial practices of dialogues would result in oral language proficiency.

The fact that ALTA was firmly grounded in linguistic and psychological theory is supported by Brown (2001). This is because by reviewing the activities of the teaching approach, they are presented not only in drilling short patterns but also in a variety of dialogues which learners have to listen to, repeat, and memorise. The dialogues do not only provide learners with the structure and idea of how to use a particular sentence pattern in a situation, but they also illustrate socio-cultural situations of a target language, such as greeting, opinion exchanges, likes or dislikes, and everyday topics such as weather and hobbies. The dialogue drillings will help learners to memorise which utterance is suitable for a particular situation. Through repeating and memorising the whole dialogue or some specific parts of it, learners are exposed to proper pronunciation, intonation, stress, and rhythm of the language. Thus, from these points, Brown (2001) has added that the conditioning and habit-formation models of learning were perfectly married with the mimicry drills and pattern practices of audio-lingual methodology that made ALTA firmly grounded in linguistic and psychological theory (cited in Alemi \&Tavakoli, 2013, p. 2).

In conclusion, ALTA plays an essential role in developing learners' speaking skills in a short period. This is because ALTA aim is to develop learners' communicative competence by using dialogues and exercises. Repetition of dialogues and exercises allow students to make responses quickly and accurately in spoken language (Ghofur et al., 2017).

\section{Dialogue memorisation type}

ALTA is applied through dialogue memorisation. The dialogue memorisation contains three main parts. Firstly, the context of dialogue is presented to learners. Next, the teacher will take the role of one person, while one of the students takes the other. The teacher will then ask 
questions based on the context of dialogue to each student. Lastly, learners need to rote memorise the whole dialogue in the text, and the teacher will go to each group to observe their drilling.

\section{Effect of TBLT}

Researchers discovered that TBLT could increase learners' learning motivation. This is because TBLT creates a positive learning environment to promote learners' enjoyment (McDonough \& Chaikitmongkol, 2007) and decreased learners' learning anxiety by boosting their confidence (Lopes, 2004 as cited in Bao \& Du, 2015). Besides that, Motallebzadeh and Defaei (2013), in their research, also proved that TBLT listening activities promote the improvement of listening self-efficacy among EFL intermediate learners.

Recently, there are researches done in the Teaching Mandarin as a Foreign Language (TMFL) context. For instance, Bao (2012) found that the use of TBLT can assist in increasing after school lower secondary learners' participation and spur their interests in the learning process. The same condition happens in Chinese characters learning among high-school learners, as reported by Kirkebæk (2012). Moreover, Bao and Du (2015) also proved in their study that TBLT enhances learners in term of increasing their participation, creating more opportunities for speaking, easing learners' anxiety, and enhancing enjoyment. However, there were challenges encountered by researchers, such as the lacking of Chinese pronunciation practice, difficulty in balancing learners' different preferences for learning strategies, and a lack of sufficient instructional time support.

\section{Effect of audio-lingual teaching approach}

According to the current research, it is shown that ALTA could improve learners' learning motivation. Anggraeni (2007), for instance, has demonstrated that by using ALTA, learners show great enthusiasm during the lesson, their speaking skills are improved, and they became more confident and motivated in learning the language. These improvements, according to Anggraeni (2007), can be linked to the teaching aids and materials used in the class, along with the teacher's positive reinforcement. The result of the research also showed that due to the positive reinforcement, students' intrinsic motivation is enhanced. Therefore, it can be highlighted that positive reinforcement is fundamental in allowing learners to work towards personally meaningful goals, develop positive attitudes towards the teacher, the class, the teaching method, and the language learning.

Although there had been a lot of research done on the application of the TBLT and ALTA in teaching English, there is still a lack in research that compares the effect of the application of the TBLT and ALTA in the context of TMFL, particularly on learners' learning motivation.

\section{Methodology}

This research is a quasi-experimental study that examined two or more variables over time in order to understand how changes in one variable were related to the changes in another variable. The variables here refer to TBLT and ALTA. This research also adopted the time-series design as it is useful in the examination of the typical pre- and post-treatments where observations or measurements had to be executed immediately before and after treatment (Fraenkel, Wallen \& Hyun, 2015). Convenience sampling was applied in the research due to the overlapping timetable between the teacher and researcher.

A total of 43 non-native Mandarin learners who were taking Mandarin language level 1 in Universiti Malaysia Kelantan, had become the subjects of the research. The sample was chosen 
based on specific criteria: students must have no experience in speaking, writing, listening, and reading in Mandarin, or in other words, they are zero Mandarin beginners. A screening test using the independent sample t-test was conducted on the entry test to ensure that Group A (TBLT) and Group B (ALTA) were not significant. The result of the screening test could not be generated as the $t$ value was unable to be computed because the standard deviation for both groups was zero. From this point, it could be seen that learners for both groups had zero Mandarin basic. It had shown that the threats on the internal control in terms of the groups' Mandarin proficiency were controlled.

The Adapted Willis's framework was applied in the research on the treatment group. At the same time, the control group underwent Sarıçoban's Dialogue Memorisation Method. Both teaching approaches covered four themes throughout the study: greetings, numbers, family, dates, and times. One Mandarin language teacher took part in the research by conducting the teaching, where TBLT was applied in one group (Group A), while the other group was applied with ALTA (Group B). The teacher was the person in-charged of delivering and marking the oral tests. Before the research was conducted, the teacher underwent a TBLT and ALTA training so that they would carry out the research appropriately by fulfilling the characteristics of both teaching approaches. Besides that, the Mandarin native speakers (Chinese students) who were going to assist the nonnative Mandarin learners in the tasks also underwent a briefing so that they were able to assist the learners appropriately in performing the tasks

Research instruments

The research utilised Motivational Strategies Learning Questionnaire (MSLQ) as the instrument to examine learners' learning motivation. The first part of the questionnaire was the demographic section. This part contained five items, where the main aim was to enable non-native Mandarin learners to provide their personal information, such as gender, age, Mandarin learning background, ethnic background, and their first language.

The second part was the motivational section, which consisted of 30 items in three main components; value, self-efficacy, and learning anxiety components. The value component had three subscales; intrinsic motivation, extrinsic motivation, and task value. The self-efficacy component had two subscales; self-efficacy for learning and performance and control of learning belief, as shown in Table 3.1 below. A 5-point Likert scale was utilised in this part of the questionnaire.

Table 1. Items found in the value, self-efficacy and learning anxiety component in the motivational scale

\begin{tabular}{lll}
\hline \multicolumn{2}{l}{ Value component } & Item \\
\hline 1. & Intrinsic motivation & $1,15,21,23$ \\
2. & Extrinsic motivation & $7,10,12,29$ \\
3. & Task Value & $4,16,22,25,26$ \\
\hline Self-efficacy Component & Item \\
\hline $4 . \quad$ Control of Learning Beliefs & $2,9,17,24$ \\
$5 . \quad$ Self-Efficacy for Learning and Performance & $5,6,11,14,19,20,28,30$ \\
\hline \multicolumn{2}{l}{ Learning Anxiety Component } & $3,8,13,18,27$ \\
\hline
\end{tabular}

The MSLQ was delivered to learners in two phases, which were the pre-treatment survey and post-treatment survey. The data analysis of MSLQ was done through descriptive analysis, in terms of the frequencies and percentages, using SPSS. The analysis was used to compare the changes between pre-treatment survey and post-treatment survey for TBLT and ALTA. 


\section{Result analysis}

The result of the learning motivation consisted of the accumulative result of value and selfefficacy components. All the items found in the respective subscales were accumulated according to the 5-point Likert scale, which were "not at all true of me (1), "not true of me (2), "neither true or not true of me (3)", "true of me (4)", and "very true of me (5). The accumulation of each subscale generated the result of the component. The result of learning motivation was analysed and categorised according to the level of motivation namely, very low (1-25), low (26-50), average (51-75), high (76-100) and very high (101-125).

On the other hand, the learning anxiety component of learning motivation was generated separately as the result was reversed compared to the learning motivation. The items were accumulated based the 5-point Likert scale, which was "not at all true of me (1), "not true of me (2), "neither true nor not true of me (3)", "true of me (4)", and "very true of me (5). The result of learning anxiety was analysed and categorised according to the level of anxiety, which was very low (1-5), low (6-10), average (11-15), high (16-20) and very high (21-25).

There are no changes in non-native Mandarin learners' learning motivation between pre-treatment survey and post-treatment survey of Group A (TBLT)

The descriptive analysis for the degree of learning motivation level for pre-treatment survey and post-treatment survey of Group A (TBLT) is shown in Table 4.1 below. The result shows that there is an increment in the number of learners with a very high level of learning motivation, which is from 8 students $(38 \%)$ in the pre-treatment survey to 11 students $(52 \%)$ in the post-treatment survey. Meanwhile, there was a decrement in the numbers of learners with an average level and high level of learning motivation. The average level of motivation decreases from 1 student $(5 \%)$ in the pre-treatment survey to 0 students $(0 \%)$ in a post-treatment survey. The high level of learning motivation also decreases from 12 students (57\%) in the pre-treatment survey to 10 students (48\%) in the post-treatment survey. Hence, the result shows that there is an improvement in the learning motivation of Group A (TBLT). Thus, the research hypothesis is rejected.

Table 2. Descriptive analysis for the degree of learning motivation level for pre-treatment survey and post-treatment survey of Group A (TBLT)

\begin{tabular}{lll}
\hline $\begin{array}{l}\text { Degree of level } \\
(\mathrm{n}=21)\end{array}$ & Pre-treatment survey & Post-treatment survey \\
\cline { 2 - 3 } F/\% $/ \%$ & $\mathrm{~F} / \%$ \\
\hline $26-50$ (Very low) & 0 & 0 \\
$51-75$ (Average) & 0 & 0 \\
$76-100$ (High) & $1(5 \%)$ & 0 \\
$101-125$ (Very high) & $12(57 \%)$ & $10(48 \%)$ \\
\hline Total & $8(38 \%)$ & $11(52 \%)$ \\
\hline
\end{tabular}

There are no changes in non-native Mandarin learners' learning motivation between pre-treatment survey and post-treatment survey of Group B (ALTA).

The descriptive analysis for the degree of learning motivation level for pre-treatment survey and post-treatment survey of Group B (ALTA) is shown in Table 3 below. The result shows that the level of learning motivation for pre-treatment survey and post-treatment survey remain unchanged since there are 11 students $(50 \%)$ with a high level of learning motivation and the very 
high level of learning motivation. Hence, the result shows that there are no changes in the learning motivation for Group B (ALTA), and the research hypothesis is accepted.

Table 3. Descriptive analysis for the degree of learning motivation level for pre-treatment survey and

\begin{tabular}{lll} 
& \multicolumn{2}{l}{ post-treatment survey of Group B (ALTA) } \\
\hline Degree of level & Pre-treatment survey & Post-treatment survey \\
\cline { 2 - 3 }$(\mathrm{n}=22)$ & $\mathrm{F} / \%$ & $\mathrm{~F} / \%$ \\
\hline $1-25$ (Very low) & 0 & 0 \\
$26-50$ (Low) & 0 & 0 \\
$51-75$ (Average) & 0 & 0 \\
$76-100$ (High) & $11(50 \%)$ & $11(50 \%)$ \\
$101-125$ (Very high) & $11(50 \%)$ & $11(50 \%)$ \\
\hline Total & $22(100 \%)$ & $22(100 \%)$ \\
\hline
\end{tabular}

There are no changes in non-native Mandarin learners' learning anxiety between pre-treatment survey and post-treatment survey of Group A (TBLT)

Table 4. below shows the descriptive analysis for the degree of learning anxiety level for pre-treatment survey and post-treatment survey of Group A (TBLT). The result shows that there is a decrement in the number of learners with a very high level of learning anxiety and an average level of learning anxiety. The very high level of learning anxiety with two students $(10 \%)$ in the pre-treatment survey decrease to 0 students $(0 \%)$ in the post-treatment survey. The average level of learning anxiety reduces from 11 students $(52 \%)$ in the pre-treatment survey to 8 students $(38 \%)$ in the post-treatment survey. On the other hand, the results show an increment in the number of learners with a low level of learning anxiety and a high level of learning anxiety. The low level of learning anxiety increases from $0(0 \%)$ to 1 student $(5 \%)$, while the high level of learning anxiety increases from 8 students (38\%) to 12 students $(57 \%)$. The results above indicate a decrement in the range of level of learning anxiety, where the range of level for pre-treatment survey is between the average level to a very high level, while the range of level for post-treatment survey is between a low level to a high level. Hence, the results show that there is a decrement in the learning anxiety of Group A (TBLT). Thus, the research hypothesis is rejected.

Table 4. Descriptive analysis for the degree of learning anxiety level for pre-treatment survey and posttreatment survey of Group A (TBLT)

\begin{tabular}{lll}
\hline $\begin{array}{l}\text { Degree of level } \\
(\mathrm{n}=21)\end{array}$ & Pre-treatment survey & Post-treatment survey \\
\cline { 2 - 3 } 1-5 (Very low) & 0 & $\mathrm{~F} / \%$ \\
6-10 (Low) & 0 & 0 \\
$11-15$ (Average) & $11(52 \%)$ & $1(5 \%)$ \\
$16-20$ (High) & $8(38 \%)$ & $8(38 \%)$ \\
$21-25$ (Very high) & $2(10 \%)$ & $12(57 \%)$ \\
\hline Total & $21(100 \%)$ & 0 \\
\hline
\end{tabular}

There are no changes in non-native Mandarin learners' learning anxiety between pre-treatment survey and post-treatment survey of Group B (ALTA)

Table 5 below shows the descriptive analysis for the degree of learning anxiety level for pre-treatment survey and post-treatment survey of Group B (ALTA). The result shows that there is an increment in the number of learners with a very high level of learning anxiety, from 2 students $(9 \%)$ in the pre-treatment survey to 6 students $(27 \%)$ in the post-treatment survey. Besides that, 
the result shows a decrement in the number of learners of the average level of learning anxiety and a high level of learning anxiety. The average level of learning anxiety decreases from 9 students $(41 \%)$ in the pre-treatment survey to 6 students $(27 \%)$ in the post-treatment survey. In comparison, the high level of learning anxiety decreases from 9 students $(41 \%)$ in the pre-treatment survey to 8 students (37\%) in the post-treatment survey. The low level of learning anxiety remains with a result of 2 students $(9 \%)$ during the pre-treatment survey and post-treatment survey. Hence, the results above indicate that there is an increment in the learning anxiety of Group B (ALTA), and the research hypothesis is rejected.

Table 5. Descriptive analysis for the degree of learning anxiety level for pre-treatment survey and posttreatment survey of Group B (ALTA).

\begin{tabular}{lll}
\hline \multirow{2}{*}{$\begin{array}{l}\text { Degree of motivation } \\
(\mathrm{n}=22)\end{array}$} & Pre-treatment survey & Post-treatment survey \\
\cline { 2 - 3 } & $\mathrm{F} / \%$ & $\mathrm{~F} / \%$ \\
\hline $1-5($ Very low) & 0 & 0 \\
$6-10$ (Low) & $2(9 \%)$ & $2(9 \%)$ \\
$11-15$ (Average) & $9(41 \%)$ & $6(27 \%)$ \\
$16-20$ (High) & $9(41 \%)$ & $8(37 \%)$ \\
$21-25$ (Very high) & $2(9 \%)$ & $6(27 \%)$ \\
\hline Total & $22(100 \%)$ & $22(100 \%)$ \\
\hline
\end{tabular}

\section{Discussion and conclusion}

The findings suggested that there is a negative relationship between learning motivation and learning anxiety. This led this research to examine the effects of TBLT and ALTA on both learning motivation and learning anxiety component. In learning motivation, it could be seen that there was an increase in the number of learners of Group A (TBLT) with a very high level of motivation in the post-treatment survey. Whereas, the number of learners in Group B (ALTA) with a high level of learning motivation and a very high level of motivation remained unchanged. On the other hand, for learning anxiety, Group A (TBLT) had a decrement in the numbers of learners with a very high level of learning anxiety. In contrast, Group B (ALTA) had an increment in the numbers of learners with a very high level of learning anxiety.

The increment in Group A's (TBLT) learning motivation in contrast to the decrement in learning anxiety could be explained by Jain and Sidhu (2013) where the increased level of learning anxiety would decrease the students' level of motivation or vice-versa regardless of their discipline, gender, and language. Moreover, the increment in learning motivation might be caused by the application of TBLT. This is because the tasks in TBLT are designed to be real, meaningful and learner-centred (Skehan, 1998, as cited in Thanh \& Huan, 2012). It was also influenced by the communicative task with the Mandarin native speakers (Chinese students) in real situations during the research that made learners to be highly motivated. At the same time, the learners' high motivation when completing the tasks made them work towards personally meaningful goals where they attained the tasks at an intermediate level of difficulty, challenging, but achievable to enhance their motivation (Thanh \& Huan, 2012). This condition is supported by Bao and Du (2015) in their research findings. The findings were based on the participants' self-report in interviews about how TBLT could help learners in terms of increasing participation, creating more opportunities for speaking, and enhancing learning enjoyment, which improves learners' confidence and eases their learning anxiety.

Although previous research showed that ALTA could increase learners' learning motivation, however, in this study, it was discovered that the number of learners with a high level of learning motivation and a very high level of learning motivation maintained while learning 
anxiety decreased. These phenomena are interrelated to the characteristics of ALTA, which focused on language drilling. When the contents of learning have accumulated over time, learners can hardly remember what they had learned in the class. Moreover, the speaking activities only focused on language drilling between their friends, which did not lead to real and meaningful communication, thus making it hard to memorise the conversation and causing nervous during their learning. However, the learning motivation for Group B (ALTA) maintained, which might be because learners were used towards the application of ALTA in their previous language learning, which did not change their learning motivation.

The study found that a real communication task between Chinese native speakers and nonnative Mandarin learners can build on learners' language learning motivation. Hence, TBLT should be encouraged in language task design among teachers. Besides that, the study suggested that the duration of the research should be prolonged to a certain length of time so that influence of TBLT could be proven, whether it will have a positive or negative effect on learners' Mandarin learning motivation in the long run. Besides that, it is encouraged for researchers to have participants' selfreport because it could give a profound explanation of the situation the learners are facing when TBLT and ALTA are applied.

Declaration of conflicting interest

No potential conflict of interest was reported by the authors.

Funding acknowledgement

The author(s) only received financial support from Sultan Idris Educational University for publication of this article.

\section{References}

Alemi, M., \& Tavakoli, E. (2013). Audio Lingual Method. Proceedings of 3rd International Conference on Applied Research in Language Studies. https://sriartini46.wordpress.com/2013/06/29/audio-lingual-method/

Anggraeni, P. (2007). Audio lingual teaching as an alternative method in teaching speaking. [Master dissertation, Semarang State University]. Wordpress. https://saidnazulfiqar.files.wordpress.com/2011/10/skripsi-audio-lingual-in-teachingspeaking.pdf

Bao, R. (2012). Does task-based teaching work unconditionally? In X. Y. Du \& M. J. Kirkebæk (Eds.), Exploring task-based PBL in Chinese teaching and learning (pp. 99-111). Newcastle: Cambridge Scholars Press.

Bao, R., \& Du, X. (2015). Implementation of task-based language teaching in Chinese as a foreign language: benefits and challenges. Language, Culture and Curriculum. http://doi.org/10.1080/07908318.2015.1058392

Brown, H. D. (2000). Principles of Language Learning and Teaching (4th ed.). Addison Wesley Longman, Inc.

Chamot, A. U., Barnhardt, S., El-Dinary, P. B., \& Robbins, J. (1999). The Learning Strategies Handbook White Plains. Addison Wesley Longman.

Cheun, H. H. (2006). Problems encountered in teaching Chinese as a second language in Malaysia. Malaysia: New Era College

Chua, H. W., Lin, C. Y. \& Azlan, M. A. K. (2018). The Influence of Task-Based Language Teaching and Audio-Lingual Teaching Approach on Mandarin Language Learning 
Outcomes. PUPIL: International Journal of Teaching, Education and Learning. 2(3), 123141.https://dx.doi.org/10.20319/pijss.2018.43.123141

Dailey, A. (2009, July). Implementing Task-Based Language Teaching in Korean Classrooms Module 1 Assessment Task. https://www.birmingham.ac.uk/Documents/collegeartslaw/cels/essays/languageteaching/DailyLTMImplementingTask-

BasedLanguageTeachinginKorean.pdf

East, M. (2017). Research into practice: The task-based approach to instructed second language acquisition. $\quad$ Language $\quad$ Teaching, 50(3), 412-424. https://doi.org/10.1017/S026144481700009X

Fraenkel, J. R., Wallen, N. E., \& Hyun, H. H. (2015). How to design and evaluate research in education (9th ed.). Mc Graw Hill.

Gardner, R. C., Lalonde, R. N., Moorcroft, R., \& Evers, F. T. (1987) Second language attrition: the role of motivation and use. Journal of Language and Social Psychology, 6, 29-47.

Ghofur, A., Degeng, N. S., Widiati, U., \& Setyosari, P. (2017). The Effect of Communicative Language Teaching and Audio-Lingual Method On English Speaking Skill Across Different Learning Styles. KnE Social Sciences, 1(3), 1-7. https://doi.org/10.18502/kss.v1i3.719

Hashimoto, Y. (2002). Motivation and willingness to communicate as predictors of reported L2 use: the Japanese ESL context. Second Language Studies, 20, 29-70 .

Hung, N. V. (2014). Review of notion and framework of task-based language teaching. International Journal of English Language and Linguistics Research 2(1), 34-48. http://www.eajournals.org/wp-content/uploads/Review-of-Notion-and-Framework-ofTask-Based-Language-Teaching.pdf

Jain, Y., \& Sidhu, G. K. (2013). Relationship between anxiety, attitude and motivation of tertiary students in learning English as a second language. Procedia - Social and Behavioral Sciences, 90, 114-123. https://doi.org/10.1016/j.sbspro.2013.07.072

Jeon, I.-J. (2005). An analysis of task-based materials and performance: Focused on Korean high school English textbooks. English Teaching, 60(2), 87-109. http: // www. researchgate.net/ publication/255594998_Exploring_EFL_Teachers'_Perceptions_of_TaskBased_Language Teaching_A_Case_Study_of_Korean_Secondary_School_Classroom_Practice.

Jie Ying, K., Yan Mei, S., \& Ramli, $\overline{\text { S. }}$ (2020). The relationship between students' need and Arabic course for business purpose at Yinchuan University of China. SIBAWAYH Arabic Language and Education, 1(1), 157-165. Retrieved from http://ejornal.upsi.edu.my/index.php/ SIBAWAYH/article/view/3780

Kirkebæk, M. J. (2012). Use of tasks in teaching of Chinese characters. In X. Y. Du \&M. J. Kirkebæk (Eds.), Exploring task-based PBL in Chinese teaching and learning (pp. 111-131). Cambridge Scholars Press.

Larsen-Freeman, D. (2000). Techniques and principles in language teaching. Oxford University Press.

Leaver, B. L., \& Willis, J. (2004). Task-based instruction in foreign language education: Practices and programs. Georgetown University Press.

Lee. J. (2000). Tasks and Communicating in Language Classrooms. McGraw-Hill.

Liu, Rui (2018) "First Language Transfer in Mandarin Compositions Written by Learners with English as Mother Tongue," Chinese Language Teaching Methodology and Technology: Vol. 1: Iss.4, Article 3.https://engagedscholarship.csuohio.edu/cltmt/vol1/iss4/3 
Lopes, J. (2004). Introducing TBI for teaching English in Brazil: Learning how to leap the hurdles. In B. L. Leaver \& J. R.Willis (Eds.), Task-based instruction in foreign language education (pp. 83-95). Georgetown University Press.

McDonough, K., \& Chaikitmongkol, W. P. (2007). Teachers' and learners' reactions to a taskbased

EFL course in Thailand. TESOL Quarterly, 41(1), 107-132. https://doi.org/10.1002/j.15457249.2007.tb00042.x

Motallebzadeh, K., \& Defaei, S. (2013). The effect of task-based listening activities on improvement of listening self-efficacy among Iranian intermediate EFL learners. International Journal of Linguistics, 5(2), 24-33. https://doi.org/10.5296/ijl.v5i2.3560

Murad, T. M. (2009). The Effect of Task-Based Language Teaching on Developing Speaking Skills among the Palestinian Secondary EFL Students in Israel and Their Attitudes towards English. [Doctoral dissertation, Yarmouk University]. http://asian-efljournal.com/Thesis/Thesis-Murad.pdf

Naimah, A. (2005). Cemerlang dalam peperiksaan, lemah dalam kemahiran komunikasi: Permasalahan yang dihadapi oleh pelajar penutur bukan jati yang mempelajari bahasa ketiga. [Paper presentation]. Proceedings of ILANNS 2005 Conference.

NamazianDost, I., Bohloulzadeh, G., \& Pazhakh, A. (2017). The effect of task-based language teaching on motivation and grammatical achievement of EFL junior high school students. Advances in Language and Literary Studies, 8(2), 243-259. https://doi.org/10.7575/aiac.alls.v.8n.2p.243

Navidinia, H., Nazarloo, S. A., \& Esmaeili, Z. (2018). Using Translation in Foreign Language Classrooms: Examining its Effectiveness in Teaching Vocabulary to EFL Students. AJELP: Asian Journal of English Language and Pedagogy, 6, 1-10. https://doi.org/10.37134/ajelp.vol6.1.2018

Park, M. (2012). Implementing computer-assisted task-based language teaching in the Korean secondary EFL context. In A. Shehadeh \& C. Coombe (Eds.), Task-based language teaching in foreign language contexts research and implementation (pp. 215-241). Amsterdam: John Benjamins.

Prabhu, N. S. (1987). Second language pedagogy. Oxford: Oxford University Press.

Skehan, P. (1998). A cognitive approach to language learning. Oxford University Press.

Tan, T.G., Hairul Nizam Ismail, F. T. H. \& C. C. H. (2016). The Motivation of Undergraduates Learning Mandarin as a Foreign Language, e-Academia Journal UiTMT,5(1), 1-11. http://journale-academiauitmt.uitm.edu.my/v2/images/vol5issue12016/PID2-

TheMotivationofUndergraduatesLearningMandarin.pdf

Thanh, L.N. \& Huan, N.B. (2012). Task-Based Language Learning and Student Motivation in Vocabulary Acquisition. Language Education in Asia 3(1), 106-120. http://dx.doi.org/10.5746/LEiA/12/V3/I1/A10/Thanh_Huan

Willis, J. (1996). A framework for task-based learning. Longman.

Zhou, X. B. (2008). Duìwài hànyǔ jiàoxué dăolùn. The Commercial Press. 